\title{
Enfrentamento do adolescente em condição crônica: importância da rede social
}

\author{
Coping of teenagers with chronic conditions: importance of social network \\ Enfrentamiento de los adolescentes en condición crónica: importancia de la red social
}

\section{Yana Balduíno de Araújo', Neusa Collet', Isabelle Pimentel Gomes', Rosenmylde Duarte da Nóbrega'}

'Universidade Federal da Paraíba. Curso de Graduação em Enfermagem. João Pessoa, PB

Submissão: 05/01/2010

Aprovação: 07/1 1/2010

\section{RESUMO}

Este estudo objetivou investigar a influência da rede social no enfrentamento do adolescente em condição crônica. PesQuisa Qualitativa cujos sujeitos foram adolescentes hospitalizados com diagnósticos de doença crônica há pelo menos um ano. Os dados foram coletados por meio de entrevista semi-estruturada e os depoimentos submetidos à análise temática. Resultados demonstraram Que o adolescente em condição crônica tem repercussões importantes em sua vida. Amigos, professores e profissionais de saúde fazem parte da rede social. Para promover autonomização ele precisa ser incluído no planejamento do seu cuidado e de uma rede social Que lhe dê suporte em suas diversas demandas nas diferentes fases da doença.

Descritores: Adolescente; Doença Crônica; Apoio Social; Enfermagem.

\section{ABSTRACT}

This study aimed at investigating the influence of social network on adolescent coping with chronic conditions. Qualitative research whose subjects were hospitalized adolescents who had a diagnosis of chronic disease for at least one year. Data were collected through semi-structured interview and depositions were submitted to thematical analyses. This research highlights that the chronic condition in adolescence brings substantial effects on their lives. Friends, teachers and health professionals are part of the social network. To promote autonomy it is necessary to include adolescents in care planning and to have a social network that supports them in various demands in different stages of illness.

Key words: Adolescent; Chronic Disease; Social Support; Nursing

\section{RESUMEN}

Esto estudio objetivó investigar la influencia de la red social en el enfrentamiento del adolescente en condición crónica. Estudio cualitativo cuyos sujetos fueron adolescentes hospitalizados que tenían un diagnóstico de enfermedad crónica durante al menos un año. Los datos fueron recogidos a través de entrevistas semi-estructuradas y los discursos fueron sometidos a análisis temático. Este estudio pone de relieve que los adolescentes con enfermedades crónicas tienen un impacto importante en su vida. Amigos, profesores y profesionales de la salud forman parte de la red social. Para promover la autonomía los adolescentes necesitan ser incluidos en la planificación de su cuidado y de una red social Que da apoyo a sus diversas demandas en las diferentes etapas de la enfermedad.

Descriptores: Adolescente; Enfermedad Crónica; Apoyo Social; Enfermería 


\section{INTRODUÇÃO}

O período da adolescência caracteriza-se como um momento de transição para a vida adulta, portanto, esse período geralmente é frustrante e difícil para o jovem saudável, sendo ainda mais complicado àQueles em condição crônica. A simultaneidade da adolescência e da doença crônica caracteriza uma crise existencial, sobrepondo-se à outra crise, representada pela enfermidade muitas vezes incurável e respectiva necessidade de tratamento continuado $^{(\mathrm{I})}$

A doença crônica na adolescência pode desencadear repercussões físicas, psicológicas e sociais, bem como a necessidade de atenção singular no processo de hospitalização. Mesmo com o avanço atual no diagnóstico e terapêutica, estas doenças implicam um processo de adaptação permanente, o que muitas vezes não condiz com seu processo de crescimento e desenvolvimento, alterando sua rotina ${ }^{(2)}$.

O tratamento dessas doenças geralmente é prolongado, complexo, exigindo cuidados constantes em relação à terapêutica em si e a determinantes Que possam agravar o estado de saúde. Quando há necessidade de hospitalização, o adolescente é separado do convívio com seus familiares, amigos, colegas e da escola. Portanto, é nesse contexto que precisa cotidianamente adaptar-se às situações decorrentes da condição crônica. Esses aspectos interferem na saúde física do adolescente, bem como alteram sua convivência com a família, os amigos e a escola podendo desencadear processos de fragilidade emocional e isolamento social(3).

Além dos aspectos já descritos, há outros envolvidos, especialmente Quando o local de atendimento é um hospital público, pois, na maioria dos casos, esses adolescentes fazem parte de comunidades menos favorecidas, Que vivenciam falta de informação, desconhecimento dos seus direitos ${ }^{(4)}$. A vulnerabilidades desses jovens aumenta Quando suas famílias são desagregadas e eles geralmente não possuem um projeto para suas vidas ${ }^{(5)}$.

Sob esta ótica, a dinâmica do cuidado ao adolescente em condição crônica deve ser ampliada, envolvendo-o em sua totalidade, unicidade e diversidade. Planejar o cuidado em saúde nessas condições requer a existência de uma rede social Que dê suporte ao adolescente e sua família no atendimento de suas demandas no cotidiano.

Para compreender essas relações, é preciso diferenciar rede social de apoio social, pois, embora sejam conceitos inter-relacionados, carregam diferenças entre si. A "rede social refere-se à dimensão estrutural ou institucional, ligada a um indivíduo. O apoio social encontra-se na dimensão pessoal, sendo constituído por membros desta rede social efetivamente importante para as famílias. Rede social é uma teia de relações que liga os diversos indivíduos que possuem vínculos sociais, propiciando que os recursos de apoio fluam através desses vínculos"(6).

Assim, a rede social é entendida como: "um sistema de apoio constituído por diferentes pessoas pertencentes à comunidade na Qual o portador da doença crônica se insere os integrantes da rede oferecem diferentes formas de apoio, emocional, material e educacional como forma de compartilhar experiências, surtindo um efeito direto sobre o bem-estar do indivíduo e do grupo ao Qual ele pertence" $^{(7)}$.

Essa perspectiva implica compreender o apoio social como um processo de interação entre pessoas ou grupos de pessoas, Que por meio do contato sistemático estabelecem vínculos recebendo apoio material, emocional, afetivo, contribuindo para o bem estar recíproco. O apoio social realça o papel Que os indivíduos podem desempenhar na resolução de situações cotidianas em momento de crise $^{(8)}$.

Diante de todas as adversidades provocadas pela condição crônica na adolescência este é um tema relevante para reflexão da organização do processo de trabalho da enfermagem, especialmente naqueles locais onde a demanda por internamento desses jovens é significativa. Autores descrevem Que as adversidades provocadas pela condição crônica poderiam ser minimizadas se o adolescente fosse atendido em um ambiente específico, sendo assistido por profissionais capacitados para reconhecer suas necessidades, contribuindo para o seu restabelecimento e reduzindo o impacto da hospitalização ${ }^{(9)}$.

Nesse sentido, estudo realizado sobre a doença crônica e suas marcas na infância as autoras salientam que "é preciso estruturar estudos com crianças portadoras de doenças crônicas e não somente sobre essas crianças. Construir instrumentos que possibilitem a aproximação, e apreensão de seus modos de viver, apropriação do espaço social e experiência com o adoecimento. Todo esse processo não merece ser negado, disfarçado ou escondido, mas pode ser adequadamente manejado pela família, recebendo suporte profissional caso necessário para isso, e pelo serviço de saúde ${ }^{(10)}$.

Baseado nesta problemática, neste estudo objetivou-se investigar a influência da rede social no enfrentamento do adolescente em condição crônica.

\section{MÉTODO}

Tratou-se de uma pesquisa de natureza Qualitativa. As metodologias de pesquisa Qualitativa são "aQuelas capazes de incorporar a Questão do significado e da intencionalidade como inerentes aos atos, às relações, e às estruturas sociais, sendo essas últimas tomadas tanto no seu advento Quanto na sua transformação, como construções humanas significativas"(11).

A pesquisa de campo foi realizada em uma unidade de internação pediátrica de um Hospital Escola do Estado da Paraíba. Os sujeitos da pesquisa foram Quatro adolescentes hospitalizados, com idade variando entre 14 e 18 anos. A seleção desses adolescentes seguiu aos seguintes critérios: possuir o diagnóstico médico de doença crônica há pelo menos um ano, aceitar participar da pesQuisa e ter a autorização dos pais ou responsáveis para sua participação.

Atendendo à Resolução no 196/96 do Ministério da Saúde, Que regulamenta a realização de pesQuisas envolvendo seres humanos $^{(12)}$, e a Resolução 3 1 1/2007 do Conselho Federal de Enfermagem $^{(13)}$ o projeto de pesQuisa deste estudo foi aprovado junto ao Comitê de Ética em Pesquisa do hospital em estudo tendo obtido parecer favorável sob o $n^{\circ} 128 / 07$. Os acompanhantes responsáveis pelos adolescentes hospitalizados assinaram o Termo de Consentimento Livre e Esclarecido.

O período de coleta do material empírico foi de dezembro 2008 a maio de 2009 utilizando-se como instrumento a entrevista semiestruturada. O roteiro foi testado por meio de estudo piloto e cons- 
tava de duas Questões norteadoras, a partir das Quais os adolescentes discorreram sobre o seu enfrentamento em relação à condição crônica: "Quais mudanças você percebe em sua vida em decorrência da doença crônica"?, "Como é o seu relacionamento com as pessoas da família, sua escola, da sua comunidade e os profissionais de saúde"? As entrevistas foram gravadas e transcritas na íntegra para posterior análise.

A análise do material empírico seguiu os princípios da interpretação temática ${ }^{(1)}$. A organização dos dados deve ser feita englobando o conjunto do material coletado. Portanto, realizou-se a transcrição das entrevistas gravadas e procedeu-se uma primeira organização dos relatos em determinada ordem, já iniciando uma classificação.

Assim, traçamos o mapa horizontal do material. Posteriormente, realizou-se leitura exaustiva e repetida dos textos, fazendo uma relação interrogativa com eles para apreender as estruturas de relevância. Esse procedimento permitiu elaborar uma classificação por meio da leitura transversal. Em seguida, a partir das estruturas de relevância, processou-se o enxugamento da classificação, reagrupando os temas mais relevantes e realizou-se a análise final.

A fim de garantir o anonimato dos sujeitos da pesquisa, os adolescentes foram identificados pela letra "A" entre parêntesis, acompanhada pelo numeral ordinal Que se referiu à ordem de realização das entrevistas. Assim, o Adolescente entrevistado I aparecerá no texto com (Al), Adolescente entrevistado 2 (A2) e assim sucessivamente.

Os diagnósticos de doença crônica, o sexo e a idade de cada um dos Quatro adolescentes foram: (Al): Púrpura Trobocitopênica Idiopática, sexo feminino, 15 anos; (A2): Diabetes Melitus tipo I, sexo feminino, 16 anos; (A3) Talassemia, sexo feminino, 18 anos e (A4): Talassemia, sexo feminino 17 anos. O tempo de diagnóstico médico da doença crônica variou entre 4 e 18 anos.

\section{RESULTADOS E DISCUSSÃO}

Para o enfrentamento da condição crônica, a literatura ressalta Que as famílias necessitam de diferentes tipos de apoio: afetivo, econômico e, principalmente, da equipe responsável pelo tratamento $^{(14)}$. Neste estudo, de acordo com os depoimentos dos adolescentes, as redes e os apoios sociais foram muito significativos e as categorias identificadas a partir da análise do material empírico foram: repercussão da doença crônica para o adolescente e rede social do adolescente no enfrentamento da condição crônica.

\section{Repercussão da doença crônica para o adolescente}

As transformações Que ocorrem na vida de um adolescente Que possui uma doença crônica exigem mudanças de hábitos e atitudes, ou seja, adaptações em função do tratamento e dos cuidados à sua nova condição de saúde. Para tanto, ele deve aprender a lidar com a situação se valendo das estratégias e habilidades de enfrentamento Que possui ${ }^{(15)}$.

Preciso me controlar, parar para pensar, e ficar Quieta mesmo, sem fazer nada disso [...] Ter um pouco de paciência, e tentar não fazer o Que eu fazia antes [...] as pessoas me veem normal, mas por dentro existe outra pessoa, mais triste. Tem gente Que diz: - Olha, nem parece Que é doente!. É bom não parecer ser

\section{doente, mas tenho Que ser. (Al)}

O conflito entre a aceitação da limitação imposta pela doença e a vontade de poder realizar atividades antes permitidas é explicitado no depoimento acima. O adolescente enfrenta limitações em suas atividades cotidianas a partir do diagnóstico da doença a fim de mantê-la sob controle. Para isso, lança mão de mecanismos de autogoverno frente aos seus desejos e anseios, porém mostra-se emocionalmente vulnerável nessa situação buscando fazer com Que outras pessoas não o vejam como doente.

A percepção Que tem de si próprio é diferente da Que os outros tem dele. Como a percepção é uma função cerebral Que tem relação com as vivências passadas de um ser humano ${ }^{(16)}$, neste caso, identificou-se Que a doença crônica interfere na vida e no cotidiano do adolescente. Embora busque levar uma vida como outras pessoas de sua faixa etária, tem consciência de Que sua doença exige cuidados especiais e Que esses cuidados também são de sua responsabilidade. Essa sobrecarga emocional pode desencadear conflitos internos Que precisam ser identificados para que o adolescente receba apoio emocional e tenha suporte para o enfrentamento dessa situação.

No âmbito emocional e social, o adolescente também passa por transições desencadeadoras de conflitos internos e externos ${ }^{(17)}$. Nesse sentido, a convivência com a doença crônica invade todos os espaços da vida do adolescente, mediando também suas relações com outras pessoas, reclamando uma reorganização interna profunda para reconstruírem seus modos de andar a vida os Quais devem comportar as implicações e os limites impostos pela doença. Essa reorganização, em geral, implica o envolvimento da família, dos amigos, da escola, enfim, de suas relações sociais.

Ao explicitarem seus sentimentos em relação à condição crônica os adolescentes apontam fragilidade, solidão e tristeza. Por se tratar de sentimentos negativos e Que não contribuem para o enfrentamento da situação, mas Que geram ansiedade, aflição e sensação de perda, os adolescentes precisam do suporte da rede social para superá-los, pois esses "sentimentos provocam insatisfação com o novo modo de viver"(18).

\section{Eu tenho raiva de mim mesma. (A2)}

Ao trazer o conteúdo de sentir raiva de si mesmo o adolescente está demonstrando sua necessidade de suporte emocional, pois, provavelmente, esse sentimento está relacionado a outro, o de sentirse culpado por ser doente. Nesses processos a escuta é uma ferramenta indispensável para os profissionais de saúde a fim de identificarem suas angústias, medos, fantasias e lançarem mão de recursos para ajudá-lo a elaborar tais sentimentos, pois o Que o adolescente em condição crônica relata não pode ser menosprezado ${ }^{(19)}$.

O depoimento abaixo reflete as dúvidas Que surgem na vida dos jovens Quando se imaginam no futuro, diante do desejo de gerar filhos e possuir uma família.

Só tenho dúvida daqui para a frente, se no futuro eu posso ter filhos, se um dia eu casar. Às vezes elas (referindo-se às médicas) dizem que eu posso, mas eu fico na dúvida. (Al)

Por serem acometidos por uma enfermidade crônica podem 
relacionar a existência da doença com a impossibilidade de realizar seus desejos e sonhos. Porém, isso nem sempre é condizente com a realidade, tendo em vista Que dependendo do tipo da enfermidade, é possível gerar filhos e formar uma família.

Apreender essas transformações nas vivências diárias do adolescente implica compreender as repercussões no modo como ele se relaciona com o mundo. Negar a doença na tentativa de ajudar o adolescente a não sofrer, reforça ainda mais a solidão e a fragilidade deste, inviabilizando a reorganização emocional das diferenças vivenciadas. Assim, o profissional de saúde, como cuidador desses jovens, precisa apreender as demandas de cuidado ampliadas para Que as dúvidas Que estes possuem sobre o presente ou o futuro com a doença possam ser desmistificadas.

Nesse sentido, é importante aos cuidadores reconhecer o momento de cada um e o contexto em Que está situada a pessoa doente, assim como compreender sentimentos e experiências diante da realidade vivida, de modo a contribuir para Que os jovens possam ter uma vida tranquila sem Que a doença atrapalhe o seu desenvolvimento $^{(18)}$.

Os sentimentos positivos também marcam os relatos dos adolescentes. A esperança desses jovens frente ao tratamento da doença revela o desejo de vivenciar futuramente experiências que possam facilitar o enfrentamento cotidiano da mesma. Para tanto, eles sugerem tecnologias em saúde Que podem ser desenvolvidas com o propósito de possibilitar maior liberdade nas atividades cotidianas, diminuição do tempo de internação hospitalar além de facilitar a desconstrução dos sentimentos de diferença e vergonha Que alguns jovens possuem por precisar se medicar em locais além do lar.

Se tivesse (o remédio) em comprimido seria melhor, porque era só tomar o sangue e voltar para casa. Eu poderia ficar em casa, ir para o colégio, voltar... Sabe? (A3)

Assim, já Que eu tenho essa doença, o meu sonho era parar de tomar injeção, só tomar comprimido, somente. PorQue Quando eu viajar levo o comprimido, e eu nem precisava mais aplicar a injeção. Eu teria menos vergonha. (A2)

Para Que o adolescente não se sinta tão limitado e sobrecarregado emocionalmente necessita receber apoio e ajuda dos profissionais de saúde e da família, de modo a amenizar o sofrimento ${ }^{(20)}$

É significativa a confiança Que os adolescentes depositam em Deus e esperam ser curados pela fé. Acreditar Que podem contar com forças espirituais traz sentimentos de conforto, pois a espiritualidade pode contribuir para produzir sentimentos de esperança ou de aceitação da condição imposta pela doença ${ }^{(21)}$.

Tem vez que eu fico num canto pedindo a Deus para curar minha doença. (A2)

A rede social desses adolescentes precisa estar atenta às necessidades dos mesmos, procurando identificar sentimentos positivos e negativos, criando um contexto para minimizar o sofrimento, proporcionando reflexões sobre suas vidas, auxiliandoos desconstruir os aspectos Que não contribuem para o enfrentamento efetivo da doença crônica. Estudos ${ }^{(18,20)}$ apontam Que o apoio da família e de outras redes sociais é fundamental para manter o equilíbrio emocional do adolescente.

Cabe aos profissionais de saúde, como integrantes da rede social, facilitar trocas de saberes, promover a educação em saúde e desenvolver estratégias para melhoria da Qualidade de vida dos adolescentes em condição crônica.

Conhecer o saber do adolescente e entendê-lo ajudará a equipe de saúde a envolver-se em um processo de comunicação interativo, no Qual a escuta Qualificada e individualizada de como cada jovem concebe sua doença e seus demais significados, contribuirão para a assistência humanizada.

Nesse sentido, o diálogo se apresenta como ferramenta indispensável. "Não basta, nesse caso, apenas fazer o outro falar sobre aquilo que eu, profissional de saúde, sei que é relevante saber. É preciso também ouvir o Que o outro, Que demanda o cuidado, mostra ser indispensável Que ambos saibamos para Que possamos colocar os recursos técnicos existentes a serviço dos sucessos práticos almejados"(22).

Portanto, o cuidado de enfermagem nessa perspectiva poderá promover a independência do adolescente para cuidar de si e assumir uma posição de compartilhamento de conhecimento, ações e apoio. Essas atitudes são favoráveis à autonomização do adolescente no cuidado e na instrumentalização da sua rede social.

Rede social do adolescente no enfrentamento da doença crônica Uma das estratégias de enfrentamento mais citadas pelas crianças e adolescentes com doença crônica é a busca de suporte social junto aos amigos, à família e aos profissionais de saúde, já Que eles representam apoio e podem auxiliar nas diferentes fases da doença ${ }^{(23)}$. Esses dados são corroborados neste estudo, conforme depoimento a seguir:

Momentos de alegria ficar perto deles (amigos), converso com minhas amigas, brinco, faço um monte de coisas. Uma das minhas amigas, uma bem próxima, ela me dá confiança, porQue ela é bem calma e me deixa calma também. Já é uma boa ajuda! Me dá mais vontade de conversar com ela. Me dá mais vontade de continuar e de não desistir. (AI)

Ela (uma amiga) me dá os deveres (atividades escolares), a gente escreve e fica estudando para as provas, fizemos os trabaIhos. (A4)

"Os momentos de alegria", conforme citado no depoimento, podem ser entendidos como estratégia de enfrentamento, já Que a possibilidade de contar com outra pessoa, a amiga nesse caso, fortalece o equilíbrio emocional, a relação social do jovem, revigorando suas forças para não desanimar. "É comum a descrição de sentimentos de solidariedade entre os amigos"(24). A cooperação e aproximação dos amigos é um dos suportes importantes na formação da rede social dos adolescentes para o enfrentamento da condição crônica. Os amigos passam a fazer parte dessa rede social a partir do momento Que se sensibilizam e auxiliam os adolescentes na superação das adversidades cotidianas na convivência com a doença crônica.

No ambiente familiar a contribuição advinda dos pais pode se refletir em um sentimento de superproteção, o Que deve ser evita- 
do, pois o adolescente com doença crônica carece de independência e responsabilidade. O cuidado dos pais é indispensável, o apoio social oferecido pela família é expressivo na pessoa da mãe, geralmente por estar mais próxima e presente durante o tratamento ${ }^{(18)}$ Contudo, o jovem precisa construir autonomia para o cuidado de si, e não ficar dependente do cuidado da família, o Que pode levá-lo a se sentir incapaz de enfrentar circunstâncias cotidianas sozinho.

Minha mãe fica triste [...] Mãe tem cuidado em mim, não deixa eu sair para canto nenhum. Eu só posso sair se for para chegar no mesmo dia [...] até meu irmão tem vez Que ele arenga (briga, implica) comigo. Mãe falou com ele, porque o doutor disse Que eu não podia ter raiva Que a diabete sobe de uma vez. (A2)

A doença de um filho afeta toda a família em diferentes intensidades para cada membro, e as outras pessoas do seu convívio. Os pais vivem sentimentos de preocupação, ansiedade, tristeza e sofrimento. Estudos ${ }^{(15,17-18)}$ ressaltam Que a maneira como a família lida com a situação influenciará a criança ou o adolescente na aceitação ou na negação da doença. É melhor ela (criança/adolescente) compreender suas limitações do Que se revoltar com seu estado, como também não utilizar mecanismos de superproteção ${ }^{(20)}$.

A superproteção dos pais, os sentimentos de tristeza e a indiferença dos irmãos, são aspectos Que precisam ser modificados, tendo em vista Que o jovem com doença crônica precisa de um ambiente domiciliar seguro e estruturado para Que o cuidado seja apropriado. Cabe aos profissionais de saúde e aos demais integrantes da rede social intervir nesse aspecto, apoiando a família e fortalecendo-a na superação de suas dificuldades, pois "a família é percebida como fundamento para o equilíbrio de seus membros, fortalecendo vínculos e as redes de sociabilidade"(2l).

Portanto, é preciso que a rede social conheça as demandas de cada jovem e da família em sua individualidade, e esteja apta para identificar seus potenciais no Que concerne a ações facilitadoras, isto é, aQuelas Que podem contribuir para fortalecer a confiança na relação com o grupo, resultando em atitudes mais firmes frente ao tratamento ${ }^{(25)}$. Além de despertar no jovem o Que há de melhor em si, cabe aos cuidadores, sempre Que possível, reduzir os determinantes negativos, os Quais modificam a auto-relação do jovem com ele mesmo e dele com os outros.

Os médicos conversaram tudo e chegaram num acordo de eu tomar hormônio para desenvolver. Então, eu gostei da idéia (risos). Pediram os exames, deram entrada na secretaria de saúde e eu vou tomar hormônio. Então, eu acho que vai melhorar um pouco. Esse tratamento é só para eu crescer porque como a doença não tem cura nenhuma, o tratamento continua o mesmo, é minha mesmo. Então, eu gostei! Eu acho Que vai ser melhor, poder vestir as roupas que eu Quero, os sapatos que eu Quero. Então, eu acho que vai ser melhor. Eu Queria crescer mesmo, porQue eu não sei como é que é ... Eu me arrumo e me olho no espelho, e eu Queria ser grande, sabe? Eu acho Que Quando eu crescer vou gostar de me olhar no espelho. (A3)

Para o adolescente, a percepção de ter um corpo Que não corresponde ao idealizado para si e para o grupo pode causar ansiedade e isolamento social ${ }^{(18)}$. Os desejos e aspirações do adoles- cente não deixam de existir Quando ele é portador de uma doença. Nesse sentido, a rede social efetiva tem muito a contribuir para a melhoria da eualidade de vida desses jovens. Ao se sentirem apoiados e incluídos em seu meio social, estarão mais preparados e fortalecidos para enfrentar as adversidades impostas pela doença.

Os profissionais da educação são citados, neste estudo, como integrantes da rede social. O professor é visto como facilitador das atividades escolares e estimulador do seguimento das orientações referentes a restrições alimentares, o Que é fundamental diante do tratamento de algumas doenças crônicas, como diabetes e talassemia.

\section{As professoras ajudam do jeitinho delas. (A3)}

Os professores me ajudam bastante, fazem novas provas, me ajudam nas atividades atrasadas. $O$ ano passado eu estive aqui (hospital) no final do ano, eu ia desistir de estudar, mas eu não desisti. Voltei para a escola e passei para a sétima. (AI)

Lá (referindo-se à escola) a gente conversa, faz brincadeira. Tem vez que o professor, assim Quase não tem lanche lá, e o professor leva da casa dele. Ele prepara logo o meu, porque ele sabe já. (A2)

As estratégias adotadas pelo adolescente, família, profissionais de saúde e de educação, Quando integrados e articulados na atenção às demandas singulares do adolescente, formam um conjunto de possibilidades Que o fortalecem na convivência com a doença crônica e tendem a imprimir uma melhor Qualidade de vida, não somente para o adolescente, mas para todas as outras pessoas a ele vinculadas. Ações dessa natureza estimulam o adolescente a desenvolver estratégias de enfrentamento da doença, pois a subjetividade aí construída acerca de tudo o Que envolve sua condição crônica passa a ser ouvida e acolhida.

\section{CONSIDERAÇÕES FINAIS}

A doença crônica na adolescência pode fragilizar o jovem, levando-o ao descompromisso com a terapêutica necessária e com os cuidados diários Que a doença crônica requer. A rede social do adolescente em condição crônica é composta pelos amigos, familiares e profissionais de saúde e de educação, constituindo-se em um potencial significativo para influenciar positivamente no melhor enfrentamento da doença crônica.

Esta pesquisa ressalta Que o adolescente em condição crônica tem repercussões importantes em sua vida decorrentes dessa situação. Para promover autonomização ele precisa ser incluído no planejamento do seu cuidado e de uma rede social Que lhe dê suporte em suas diversas demandas nas diferentes fases da doença. A condição crônica requer uma adaptação do adolescente e de sua família a uma nova rotina. Os profissionais de saúde podem potencializar as possibilidades de enfrentamento dessa situação ajudando o adolescente e sua família a identificarem redes e apoios sociais a partir do contato com recursos disponíveis. Para tanto, implica promover ações intersetoriais e multiprofissionais formando uma grande rede social para Que a melhor utilização dos apoios reforce os mecanismos e potencialidades de enfrentamento. 
A identificação das mudanças geradas pela condição crônica na vida do adolescente, bem como da rede social e das habilidades de enfrentamento, articuladas ao processo sistemático de avaliação, são ações centrais para a efetividade de intervenções promotoras do fortalecimento das competências e autonomização do adolescente.
Assim, oportunidades de participação do adolescente no seu cuidado necessitam ser criadas, não somente no campo das técnicas de intervenção do tratamento, como também no fortalecimento dos vínculos sociais. Espaços Que possibilitem a construção, a troca e a reconstrução de saberes, são meios para alcançar essas oportunidades.

\section{REFERÊNCIAS}

1. Oliveira VZ, Gomes WB. Comunicação médico-paciente e adesão ao tratamento em adolescentes portadores de doenças orgânicas crônicas. Estud Psicol 2004; 9(3): 459-69.

2. Huerta EPN. Brinquedo no hospital. Rev Esc Enferm USP 1990; 24(3): 319-28.

3. Araújo YB. Conhecimento da família acerca da condição crônica na infância. João Pessoa: Universidade Federal da Paraíba; 2008.

4. Araújo YB, Gomes IP, Collet N, Nobrega RD. Reflexões acerca da legislação e políticas públicas voltadas à saúde do adolescente. Rev Enferm UFPE Online [serial online] 2010 [cited 2010 Jun 0 I]; 4(spe): [6 screens]. Available from: http://www.ufpe.br/ revistaenfermagem

5. Griboski RA, Guilhem D, Branco IDC. Adolescent, Sexuality and Situations of Vulnerability: One Qualitative Study. Online Braz I Nurs [serial online] 2007 Sep [cited 2009 Sep 26]; 6(0): [1 2 screens]. Available from: http://www.uff.br/objnursing/index.php/nursing/article/view/I06 I

6. Pedro ICS, Rocha SMM, Nascimento LC. Apoio e rede social em enfermagem familiar: revendo conceitos. Rev Latino-am Enferm 2008; 6(2): 324-7.

7. Marcon SS, Zani AV, Waidman MAP, Radovanovic CAT, Decesaro MN, Carreira L. Rede social e família: o olhar sensível dos enfermeiros construtores da prática. Cienc Cuid Saude 2009; 8(sup): 31 -9.

8. Viera CS, Mello DF, Oliveira BRG, Furtado MCC. Rede e apoio social familiar no seguimento do recém-nascido pré-termo e baixo peso ao nascer. Rev Eletrônica Enferm [serial online] 20 I0; I2(1): [9 screens]. Available from: http://www.fen.ufg.br/revista/vI 2/nl/vI 2nla02.htm.

9. Almeida IS, Rodrigues BMRD, Simões SMF. Desvelando o cotidiano do adolescente hospitalizado. Rev Bras Enferm 2005; 58(2): |47-51.

10. Moreira MCN, Macedo AD. O protagonismo da criança no cenário hospitalar: um ensaio sobre estratégias de sociabilidade. Ciênc Saúde Coletiva 2009; 14(2): 645-2.

I1. Minayo MCS. O desafio do conhecimento: pesquisa Qualitativa em saúde. I l a ed. São Paulo: Hucitec-Abrasco; 2009.

12. Ministério da Saúde (BR). Comissão Nacional de Ética em PesQuisa. Resolução 196, de 10 de outubro de 1996. Dispõe sobre diretrizes e normas regulamentadoras de pesquisas envolvendo seres humanos. Cad Ética Pese 1998; I (1).
13. Conselho Federal de Enfermagem (BR). Resolução COFEN 3 I I , 08 de fevereiro de 2007. Aprova a Reformulação do Código de Ética dos Profissionais de Enfermagem. 2007 [citado em 2009 Abr 25]. Disponível em: http://www.portalcofen.gov.br/ 2007/materias.asp?ArticleID =722 I \&sectionID = 34 .

14. Goldsmith DJ. Communicating social support. J Commun 2006; 56(I): 228-30.

15. Damião EBC, Pinto CMMP. "Sendo transformando pela doença": a vivência do adolescente com diabetes. Rev Latinoam Enfermagem 2007; 15(4): 5 1-7.

16. Lima AAA, Pedro ENR. Crescendo com HIV/AIDS: estudo com adolescentes portadoras de HIV/AIDS e suas cuidadoras-familiares. Rev Latino-am Enfermagem 2008; 16(3): 348-54.

17. Chaú, M. O conhecimento. In: Convite a filosofia. São Paulo: Ática; 2000. p. 151-7.

18. Almino MAFB, Queiroz MVO, Jorge MSB. Diabetes mellitus na adolescência: experiências e sentimentos dos adolescentes e das mães com a doença. Rev Esc Enferm USP 2009; 43(4): 760-7.

19. Ayres IRCM, Paiva V, França Júnior I, Gravato N, Lacerda R, Negra MD, et al. Vulnerability, Human rights, and comprehensive health care needs of young people living with HIV/AIDS Am J Public Health 2006; 96(6): I 00 I-6.

20. Pliger C, Abreu IS. Diabetes mellitus na infância: repercussões no cotidiano da criança e de sua família. Cogitare Enferm 2007; 12(4): 494-501.

21. Paula ES, Nascimento LC, Rocha SMM. Religião e espiritualidade: experiência de famílias de crianças com insuficiência renal crônica. Rev Bras Enferm 2009; 62(1): 100-6.

22. Ayres IRCM. Cuidado: trabalho e interação nas práticas de saúde. I I ed. Rio de laneiro: CEPESC/UERJ/IMS/ABRASCO; 2009.

23. Pizzignacco TMP, Lima RAG. O processo de socialização de crianças e adolescentes com fibrose cística: subsídios para o cuidado de enfermagem. Rev Latino-am Enferm 2006; I4(4): 569-77.

24. Maas T. O processo de transição do ser adolescente hospitalizado com doença crônica sob a ótica da enfermagem [dissertação]. Curitiba: Programa de Pós-Graduação em Enfermagem, Universidade Federal do Paraná; 2006.

25. Santos ECB, Zanetti ML, Otero LM, Santos MA dos. O cuidado sob a ótica do paciente diabético e de seu principal cuidador. Rev Latino-am Enfermagem 2005; 13(3): 397-406. 